\title{
Über das Stupsen, Steuern und Manipulieren von Menschen
}

\section{Eberhard Wolff}

PD Dr. rer. soc., Redaktor Kultur, Geschichte, Gesellschaft

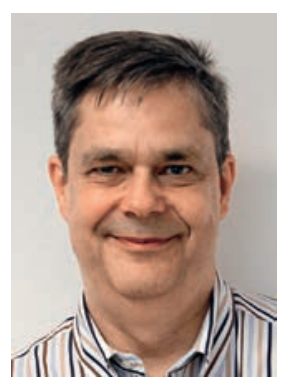

Literatur

1 Auf YouTube unter «Piano Stairs».

13. Schweizerischer Kongress für Gesund heitsökonomie und Gesundheitswissenschaften \& Zukunftsforum Gesundheit, Oktober 2016. www. skgg.ch (dort Präsentationen und Videos). Armellino D, et al. Using High-Technology to Enforce Low-Technology Safety Measures: The Use of Third-party Remote Video Auditing and Real-time Feedback in Healthcare. Clinical Infectious Diseases. 2012;54(1):1-7

4 Maier E, Reimer U. Motivation für Verhaltensänderung durch E-Nudging. Schweiz Ärztezeitung. 2016;97(43):1498-1500. Wolff E. Gesundheitskompetenz - wie viel darf's denn sein? Schweiz Ärztezeitung. 2009;90(39):1526

6 Auf YouTube unter "C tibanan" und «Odenplan».
Die zentrale Stockholmer Metrostation Odenplan wurde im Jahr 2009 noch bekannter, als man dort auf einer Treppe - neben einer Rolltreppe - eine Art Klaviertastatur anbrachte, die beim Betreten zur spontanen Freude vieler Leute Klaviertöne von sich gab. Angeblich wählten zwei Drittel mehr Passanten nun die Treppe statt der Rolltreppe [1] und traten und hopsten auf ihr herum. Das Experiment wurde zu einem der populärsten Beispiele für das sogenannte «Nudging». Das ist die Technik, Menschen weder durch Überzeugung noch durch unmittelbaren Zwang und Verbote, sondern durch vorgefundene Strukturen (hier: Spass und Spiel) zu einem als gut angesehenen Verhalten "anzustupsen».

Die Ökonomie ging bei ihren Modellen lange Zeit ausschliesslich von einem Homo oeconomicus aus, der im Eigeninteresse rational handle. Die neuere Verhaltensökonomie dagegen untersucht eine Art Homo subcorticalis bzw. Homo Bauchgefühl jenseits der rationalen Entscheidung. Nudging versucht, menschliche Verhaltensweisen mit den Modellen der Verhaltensökonomie zu steuern. Je nach Bewertung nennen andere dies beeinflussen oder manipulieren. Auch das Smartphone, das zum zehntausendsten Schritt des Tages gratuliert oder das in der Kantine besonders auffällig präsentierte "gesunde» Essen sind Formen von «Nudging». Gerade für präventivmedizinische und medizinökonomische Ziele wird "genudgt». Eine Kongressankündigung pries das Nudging kürzlich vollmundig als «Ein neuer Weg in die Zukunft» [2] an. Wege in die Zukunft können bekanntlich Prachtstrassen, Autobahnen, aber auch Buckelpisten, ja sogar Sackgassen sein. Auf dem Kongress gab es neben begeisterter Werbung und Beschreibungen laufender Projekte auch einiges an Skepsis gegenüber dem Nudging zu hören. Das Konzept sei etwa eklektisch und logisch nicht kohärent. Die Wirksamkeit sei nicht völlig belegt und sollte nicht überschätzt werden. Ich selber habe mich auch gefragt, ob so eine Klaviertastentreppe den Bahnhof Basel SBB zur Stosszeit nicht zuerst ins Chaos stürzen würde. Nach ein paar Wochen würden die Massen dann desinteressiert über die Klangsauce eilen, die allenfalls noch die dort Arbeitenden verrückt macht. Am Ende würden die Rolltreppen zur Passerelle vielleicht noch überfüllter.

Ein Referent des Kongresses erwähnte als Nudging-Beispiel die (umstrittene) Studie, bei der eine Videokamera das Waschbecken am Ausgang einer Intensivstation aufnahm. Durch die Installation vervielfachte sich die Häufigkeit des Händewaschens beim medizinischen Personal [3]. Nicht nur der Kongressbeirat und Moderator Thomas D. Szucs fühlte sich da doch etwas an Orwells «Big Brother» erinnert. Und ist es ein Zufall, wenn eine Referentin im Titel ihres Beitrags fragte, ob man «Patienten gelegentlich zu ihrem Glück zwingen» müsse? Stubsen kann eben kaum merklich in Zwang hinübergleiten. Nein, ich will das Nudgen nicht dämonisieren. Wir nudgen doch alle ständig irgendwie. Selbst dieser Text versucht Sie mit ein paar einfachen Tricks auf meine Seite zu ziehen. Aber wenn das Nudging plötzlich als gelehrte, staatstragende Grosskampagne daherkommt, müssen wir genauer hinsehen.

Ein kürzlich hier erschienener Artikel meinte, dass das Nudging Eigenverantwortung und Partizipation steigere sowie dem Bedürfnis nach Autonomie der Menschen in Fragen der Gesundheit entgegenkomme [4]. Ist es Eigenverantwortung, von aussen gesteuert $\mathrm{zu}$ werden? Für mich nicht. Fremdsteuerung ist für mich auch das klare Gegenteil von Autonomie. Eine Marionette kann nicht nicht partizipieren. Partizipation ist bewusste Teilhabe.

Systematisches Nudging negiert letzten Endes meine bewusste Entscheidungsfreiheit, meinen Verstand und meinen Wunsch nach Transparenz. In der Medizin lobe ich mir deshalb die natürlichen Feinde des Nudging, etwa den «Informed Consent» oder das Konzept der «Gesundheitskompetenz» - solange darunter mehr als informiertes Wohlverhalten, nämlich eigenständiges Nachdenken verstanden wird [5].

Ach ja: In Stockholm wird kommenden August unter der Metrostation Odenplan der neue Bahnhof der «Citibanan» eröffnet. Dort gibt es dann nur noch Rolltreppen [6]. Das ist schade für alle, die wie ich hin und wieder gerne Treppen steigen (aus eigener Entscheidung). Aber sie können wenigstens sicher sein, nicht subtil genudgt zu werden. 